\title{
Biological Activity Markers Useful in the Diagnosis of Chronic Diarrhea
}

\section{Cristina Voicu ${ }^{1 *}$ and Sorin Rugină ${ }^{2}$}

${ }^{1}$ Sfântul Apostol Andrei, Emergency County Clinical Hospital, Clinic Medical I, Constanta, Romania

${ }^{2}$ Ovidius, University of Medicine, Constanta, Romania

*Corresponding Author: Cristina Voicu, Sfântul Apostol Andrei, Emergency

County Clinical Hospital, Clinic Medical I, Constanta, Romania.
Received: November 28, 2020

Published: December 29, 2020

(C) All rights are reserved by Cristina Voicu and Sorin Rugină.

\begin{abstract}
Chronic diarrhea is a manifestation with a strong impact on patients' quality of life. A correct and early diagnosis is the desideratum of any clinician.

We evaluated 82 patients through blood tests and endoscopic investigations. Following the investigations, the patients were divided into three groups.

In these groups were analyzed the exponents of the systemic inflammatory syndrome, red cell distribution width and the fecal calprotectin in order to try to determine activity markers useful in the diagnosis of chronic diarrhea.

Keywords: Red Cell Distribution Width; Chronic Diarrhea; Faecal Calprotectin
\end{abstract}

\section{Introduction}

Chronic diarrhea can have a negative impact on the quality of life and general health. Diarrhea that lasts more than four weeks is caused by etiological diagnostic problems. If the causes are not elucidated in due time, chronic diarrhea can lead to malnutrition.

This entity is found in several gastrointestinal disorders such as colorectal cancer, inflammatory bowel disease, celiac disease, malabsorption syndromes, and irritable bowel syndrome. All these pathologies require a complex approach from the clinical doctor, because they produce a significant economic and social impact on society. Sustaining a diagnosis requires the correlation of clinical, biological, imagistic, endoscopic and histological data.

A major problem in clinical practices is the differentiation of patients with inflammatory bowel disease from those with functional disorders such as irritable bowel syndrome.

Inflammatory bowel disease (IBD) has as a common characteristic of intestinal inflammation, while representative exponents are Crohn's disease and Ulcerous-hemorrhagic colitis.
Crohn's disease is a chronic idiopathic inflammatory disease that can affect segmentally and discontinuously any section of the digestive tract, most commonly located in the ileo-cecal valve [1].

Ulcerative colitis is a chronic inflammatory disease located in the colonic mucous. In evolution, it can present outbreaks of activity and remission, but also numerous complications.

In long-term, patients have a double risk of colorectal cancer compared to the general population, a risk of up to three times higher of hospitalization, but also an increased risk of surgery at onset, especially in young people [2].

Irritable bowel syndrome is the most commonly diagnosed functional disorder worldwide, which tends to be no longer seen as a purely functional condition.

The diagnosis of irritable bowel syndrome is currently based on the Rome IV criteria published in May 2016, which is the result of a research group of over 100 international experts in functional digestive disorders [3]. 
Patients with abdominal pain, flatulence, intestinal transit disorders require numerous investigations in order to differentiate functional disorders from organic ones.

Theoretically, obtaining negative results in acute phase reactants (C-reactive protein-CRP, erythrocyte sedimentation rate-ESR, fibrinogen) should most likely exclude an organic disease [4,5]; however, studies have shown that acute phase reactants are not highly accurate markers for differentiating organic digestive diseases from irritable bowel syndrome because they reflect systemic inflammation and do not directly measure intestinal inflammation.

An alternative approach was attempted by fecal analysis of a neutrophil-derived protein called calprotectin. The results in literature describe calprotectin as a direct measure of intestinal inflammation and it does correlate with the activity of the disease in patients with inflammatory bowel disease. Thus, fecal calprotectin can be considered a screening test to differentiate irritable bowel syndrome from organic disease, because calprotectin levels rarely have normal value in patients with inflammatory bowel disease and colorectal cancer [6].

Red cell distribution width (RDW) is a parameter that quantitatively evaluates anisocytosis, defined as the variability in size of circulating erythrocytes. It is a routine parameter provided by hematology analyzers [7]. Increased RDW predicts an increased variability in erythrocyte size, and the association with low Mean corpuscular volume (VEM, MCV) suggests an iron deficiency [8]. The usefulness of RDW in IBD has already been proven to differentiate between Crohn's disease and ulcerative colitis, to differentiate between active and remission Crohn's disease, and to diagnose inflammatory disease compared to healthy patients [9-12]. The reference range for RDW-SD was between 37 and 54 FL.

\section{Purpose of the study}

The present study aimed to identify useful biological markers in the early diagnosis of chronic diarrhea, as well as the comparative evaluation of RDW as an active inflammation marker with that of exponents of systemic inflammation (C-reactive protein, erythrocyte sedimentation rate and fibrinogen) and the intestinal inflammation marker represented by fecal calprotectin in patients with chronic diarrhea.

\section{Material and Method}

Between October 2013 and September 2019, we analyzed 82 patients who presented for diarrhea lasting more than four weeks at the Constanta County Emergency Clinical Hospital, I Medical Clinic.

They were investigated by blood tests: hemoleukogram, C-reactive protein, fibrinogen, erythrocyte sedimentation rate, fecal matter: calprotectin and endoscopic investigations with biopsy where appropriate. Cases of infectious diarrhea have been eliminated.

\section{Results and Discussion}

We divided the 82 patients into 3 groups, a control group and 2 study groups.

The control group consists of 25 patients diagnosed with irritable bowel syndrome. This group includes 14 women and 11 men. Patients are between 25 and 80 years old, and the average age is 50 years.

The first study group is represented by 13 patients, who were diagnosed following investigations performed with ulcerative colitis; this group includes 6 women and 7 men. The patients are aged between 16 and 78 years, the average age being 43.76 years.

The second study group consists of 44 patients diagnosed with Crohn's disease, of which 22 are women and 22 are men. The age of the patients is between 18 and 80 years, and the average age of this group is 41.36 years.

The values of the exponents of the systemic inflammatory syndrome (ESR, PCR, fibrinogen), the value of the width of the RDW erythrocyte distribution, as well as the value of the fecal calprotectin were analyzed in the study groups.

Out of the total of 13 patients whose markers of systemic inflammation and RDW were analyzed (Figure 1), 8 patients had all three elements of systemic inflammation present, and out of the 8 , only 3 patients had increased RDW, a percentage of $37.5 \%$.

In the first study group was analyzed the correlation between the increased value of RDW compared to the normal value of RDW and the values of fecal calprotectin (Figure 2).

In the second study group represented by the 44 patients with Crohn's disease, the markers of inflammation and the value of RDW were also analyzed (Figure 3). Out of the total number of patients, 33 of them showed an increase in all inflammatory markers and from this subgroup only 12 patients had an increased value of RDW, respectively a percentage of $36.3 \%$. 


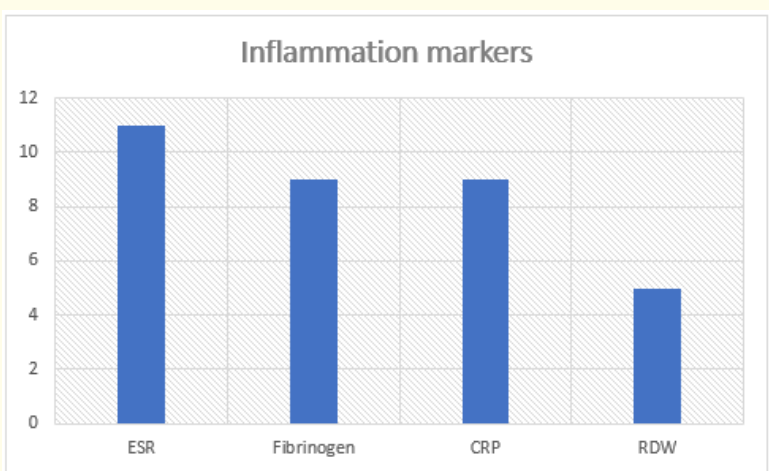

Figure 1: Reprezentation of inflammation markers in patients with ulcerative colitis.

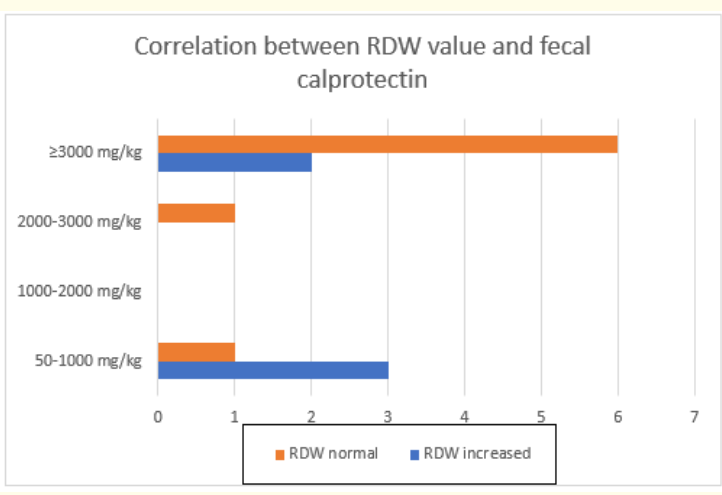

Figure 2: Distribution of patients with ulcerative colitis according to the value of RDW and that of calprotectin.

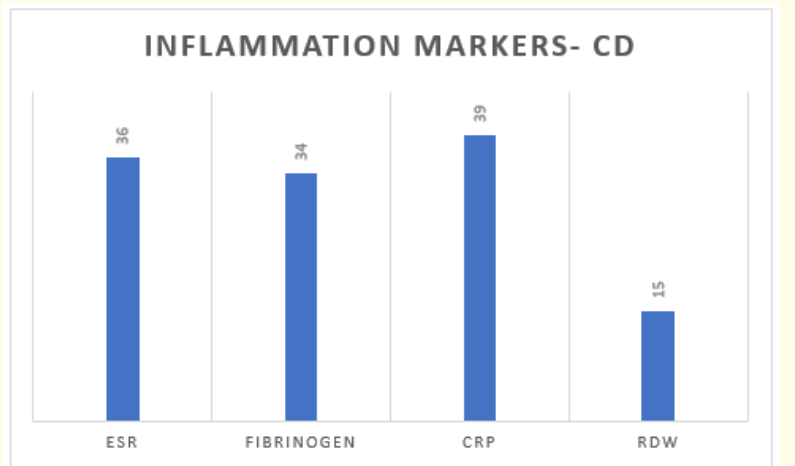

Figure 3: Reprezentation of inflammation markers in patients with Crohn'c disease.
The connection between the increased value of RDW versus the normal value of RDW and the values of calprotectin has been analyzed in the group of patients diagnosed with Crohn's disease (Figure 4).

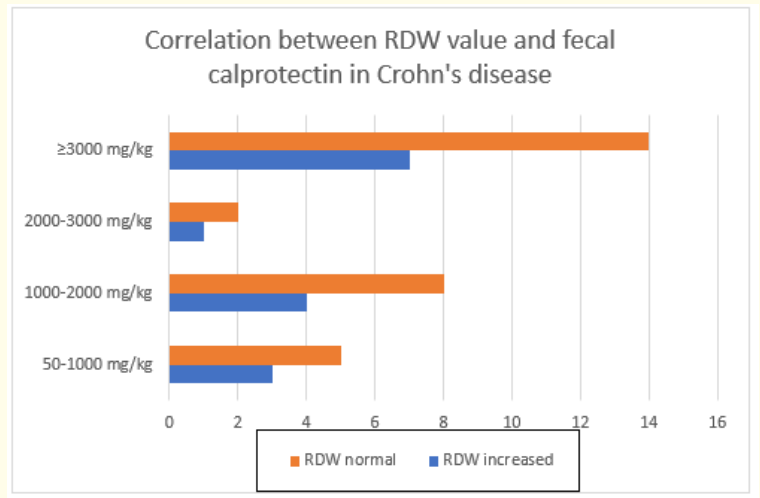

Figure 4: Distribution of patients with Chron's disease according to the value of RDW and that of calprotectin.

In the control group, respectively in the patients with irritable bowel syndrome, no significantly increased values of the components of the inflammatory syndrome were identified and all RDW values were within normal limits.

In the first study group, patients with ulcerative colitis had more normal RDW values compared to increased RDW values at a calprotectin value $\geq 3000 \mathrm{mg} / \mathrm{kg}$. If we analyze only the high values of RDW in patients with ulcerative colitis, we see that most cases were registered in the subgroup with values of calprotectin between $50 \mathrm{mg} / \mathrm{kg}$ and $1000 \mathrm{mg} / \mathrm{kg}$.

In the second study group, several normal values of RDW were registered versus the high values in the subgroup of patients with calprotectin values between $50-1000 \mathrm{mg} / \mathrm{kg}$, but also in the subgroup of patients with calprotectin value $\geq 3000 \mathrm{mg} / \mathrm{kg}$. $\mathrm{kg}$.

\section{Conclusions}

The data presented show that RDW does not correlate significantly with exponents of systemic inflammatory syndrome (ESR, fibrinogen, CRP) in Crohn's disease or ulcerative colitis.

Regarding RDW and calprotectin, it was observed that a normal value of RDW does not correlate with a lower level of intestinal inflammation in patients with Crohn's disease, instead an increased 
value of RDW predominated in patients with calprotectin $\geq 3000$ $\mathrm{mg} / \mathrm{kg}$. Based on the data obtained, we can consider RDW a new biological marker of activity in Crohn's disease.

Regarding patients with ulcerative colitis, an increased RDW value was not found in those with a calprotectin value $\geq 3000 \mathrm{mg}$ / $\mathrm{kg}$, demonstrating that the RDW value does not correlate with the level of intestinal inflammation and cannot be considered in ulcerative colitis an activity marker.

\section{Acknowledgments}

This article was not presented at any conference or sent to any journal. The research is part of the personal $\mathrm{PhD}$ thesis that is being prepared.

\section{Bibliography}

1. Catalina Mihai., et al. "Boala Crohn-afectiune medico-chirurgicala”. Jurnalul de Chirurgie, Iasi 6.2 (2016).

2. Reenaers $\mathrm{C}$ and Louis E. "Complications de la rectocolite hemorragique et impact des traitements actuels sur l'histoire naturelle de ces complications". Hepato-Gastro and Oncologie Digestive 22.2 (2015): 38-43.

3. Drossman DA and Hasler WL. "Rome IV- functional GI disorders of gut-brain interaction". Gastroenterology 150.6 (2016): 1257-1261.

4. Cabrera-Abreu JC., et al. "Performance of Blood Tests in Diagnosis of Inflammatory Bowel Disease in a Specialist Clinic". Archives of Disease in Childhood 89.1 (2004): 6-71.

5. Fagerberg., et al. "Fecal Calprotectin: A Quantitative Marker of Colonic Inflammation in Children With Inflammatory Bowel Disease". Journal of Pediatric Gastroenterology and Nutrition 45.4 (2007): 414-420.

6. Sherif El Saadany., et al. "Fecal Calprotectin as a Marker in Differentiating Irritable Bowel Syndrome from Organic Intestinal Disease". Knol beta. Refference Type: Internet Communication.

7. Lippi G., et al. "Red blood cell distribution width in heart failure: A narrative review". World Journal of Cardiology 10 (2018): 6-14.

8. Pascual-Figal DA., et al. "Red blood cell distribution width predicts long-term outcome regardless of anaemia status in acute heart failure patients". European Journal of Heart Failure 11 (2009): 840-846.
9. Molnar T., et al. "RDW can be a useful additional marker in diagnosing Crohn's disease and ulcerative colitis". Digestive Diseases and Sciences (2008): 2828-2829.

10. Oustamanolakis P., et al. "Diagnosing anemia in inflammatory bowel disease: Beyond the established markers". Journal of Crohn's and Colitis (2011): 381-391.

11. Hu D., et al. "Value of red cell distribution width for assessing disease activity in Crohn's disease". American Journal of the Medical Sciences (2014): 349.

12. Song CS., et al. "Association between red cell distribution width and disease activity in patients with inflammatory bowel disease". Digestive Diseases and Sciences 57 (2012): 1033-1038.

\section{Assets from publication with us}

- Prompt Acknowledgement after receiving the article

- Thorough Double blinded peer review

- Rapid Publication

- Issue of Publication Certificate

- High visibility of your Published work

Website: www.actascientific.com/

Submit Article: www.actascientific.com/submission.php

Email us: editor@actascientific.com

Contact us: +919182824667 